\title{
A Novel Route to Geminal Dibromocyclobutanes: Syntheses of 2- Substituted Cyclobutanone Acetals and their Reaction with Boron Tribromide.
}

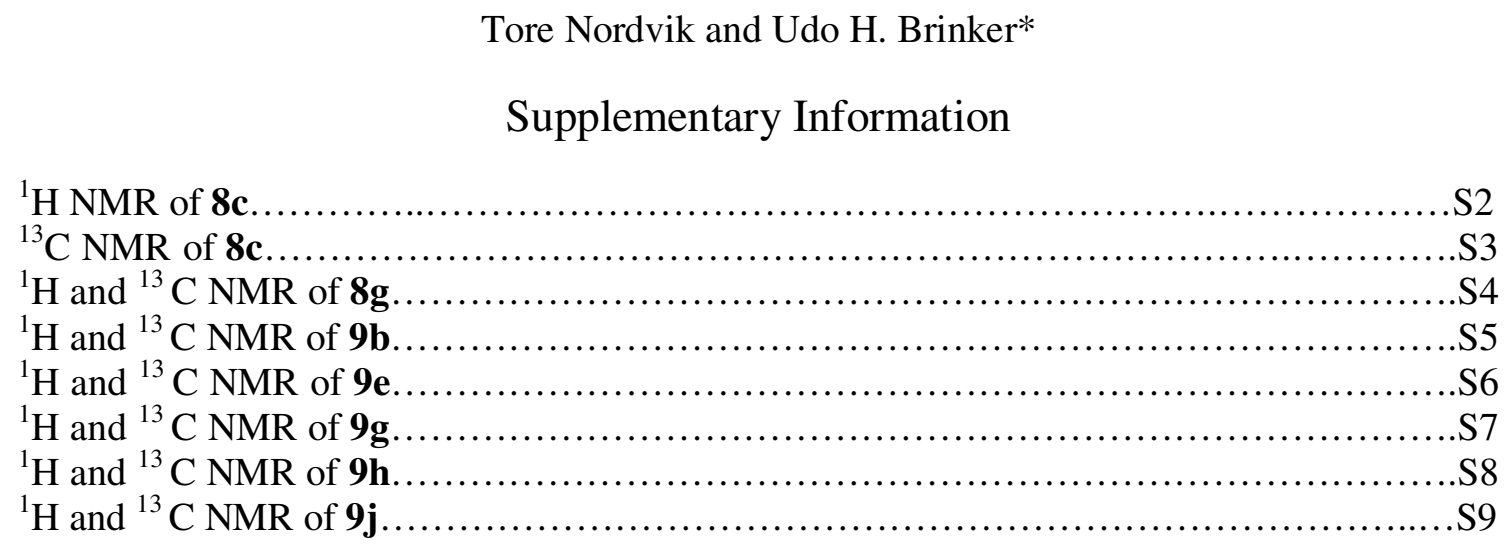


${ }^{1} \mathrm{H}$ NMR of $\mathbf{8 c}$

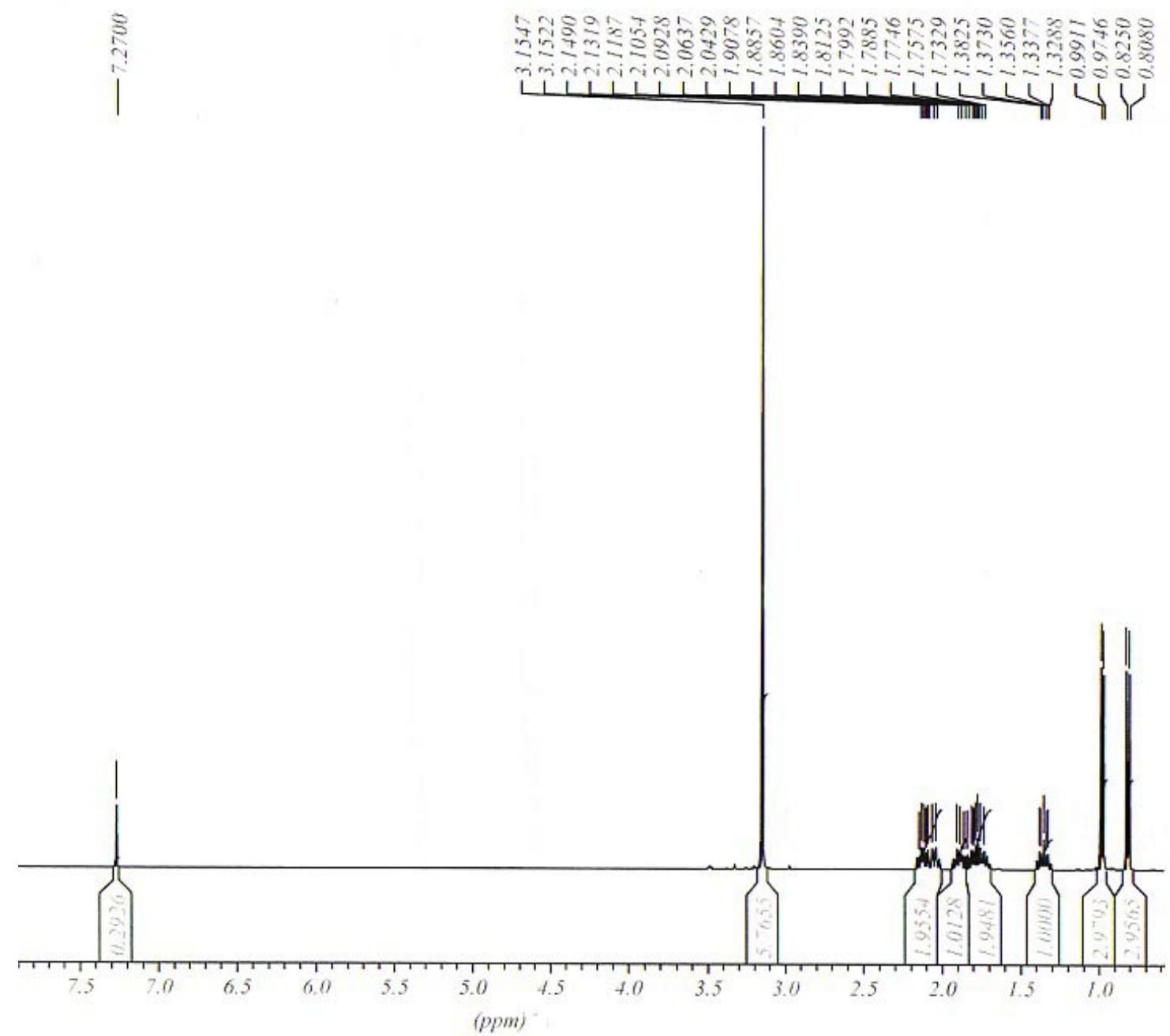


${ }^{13} \mathrm{C}$ NMR of $8 c$

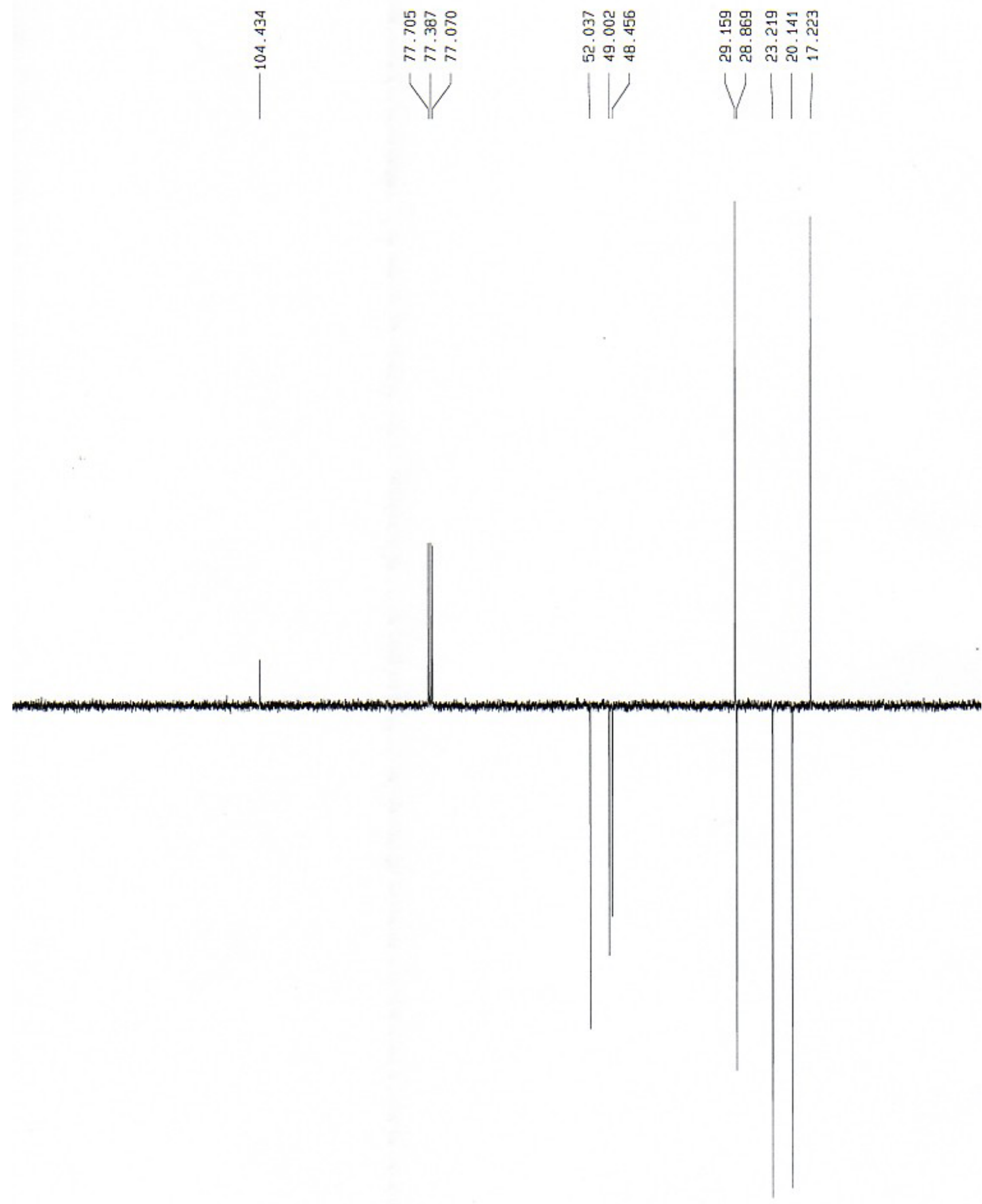




\section{${ }^{1} \mathrm{H}$ NMR of $\mathbf{8 g}$}

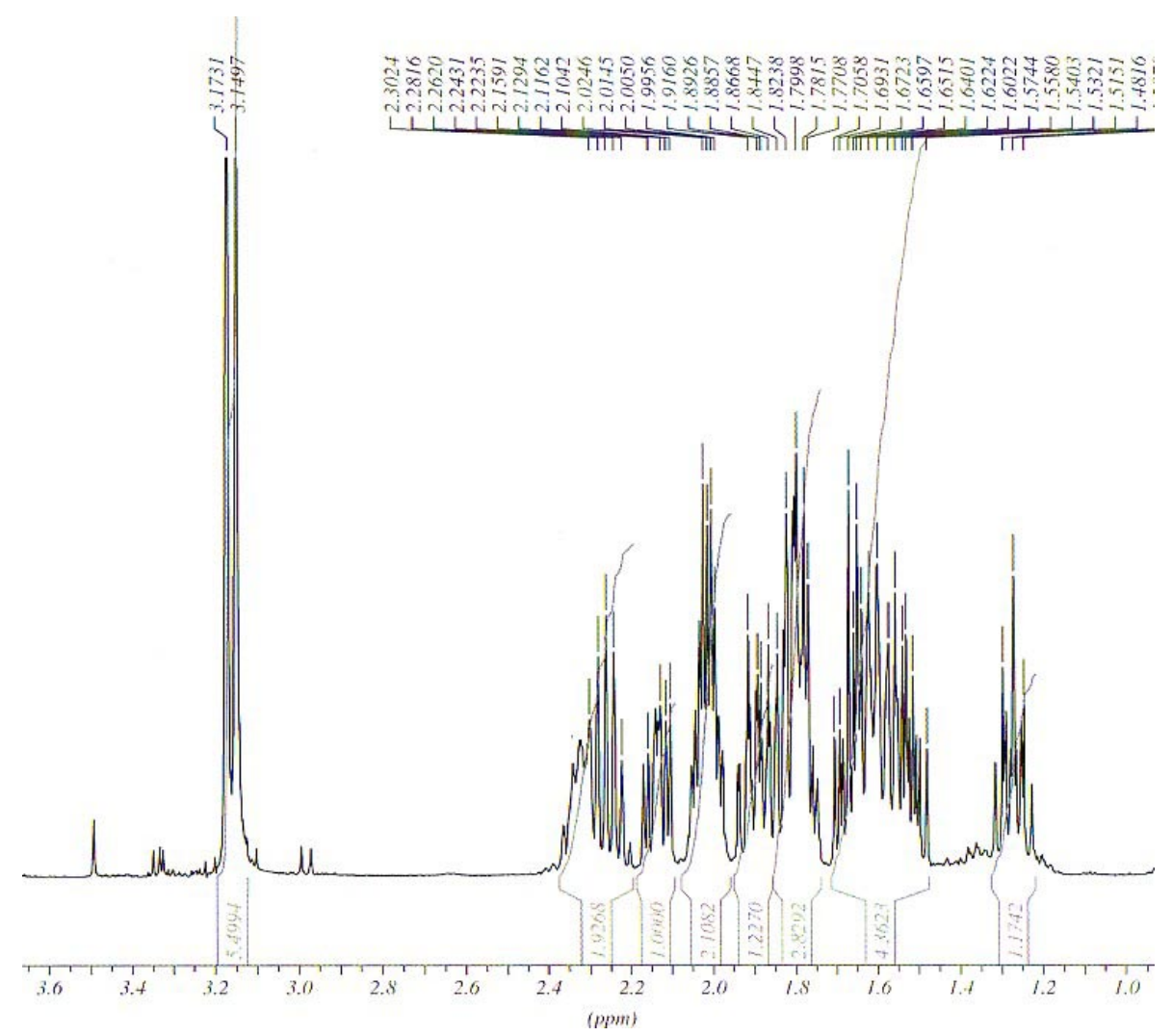

${ }^{13} \mathrm{C}$ NMR of $\mathbf{8 g}$

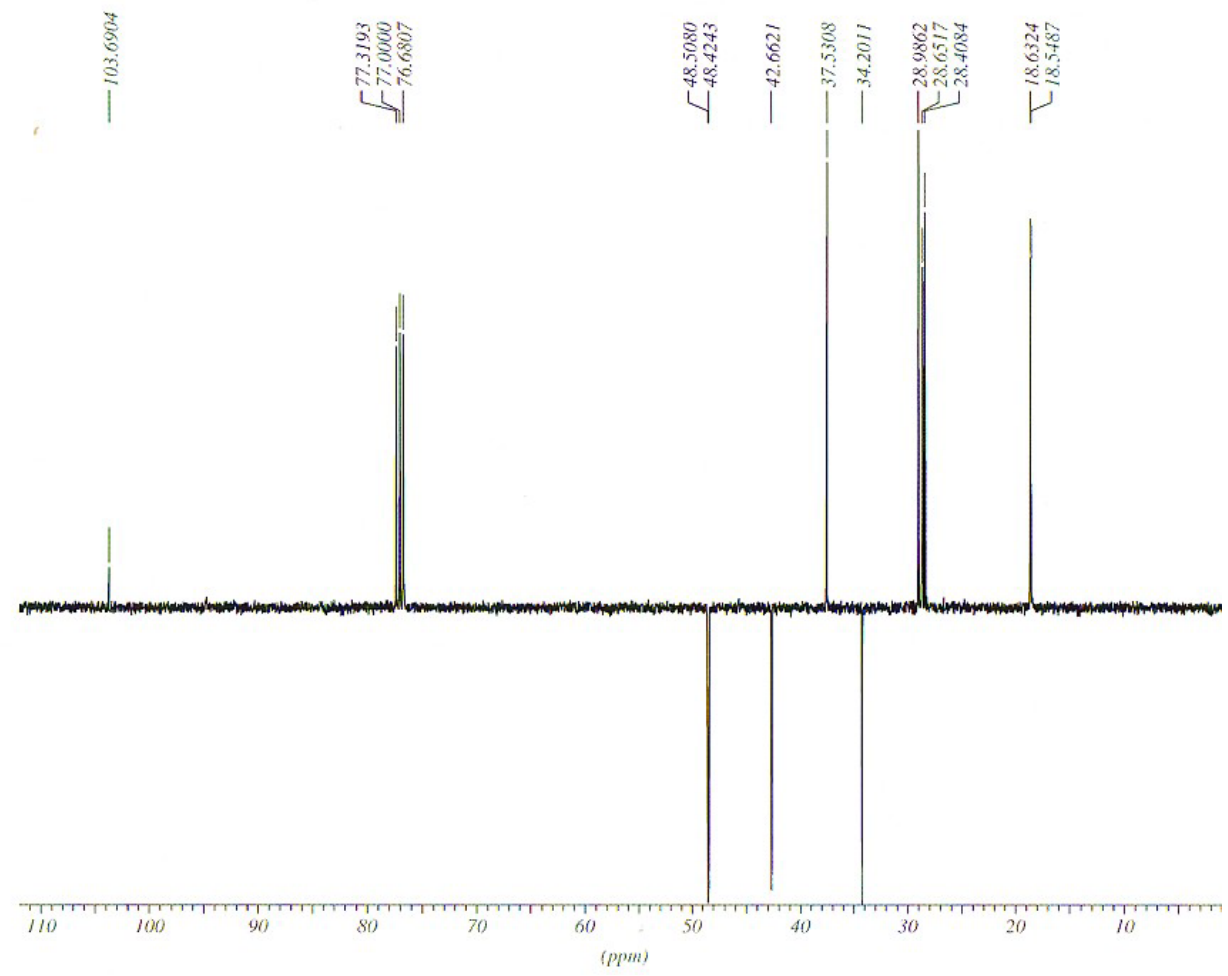


${ }^{1} \mathrm{H}$ NMR of 9b

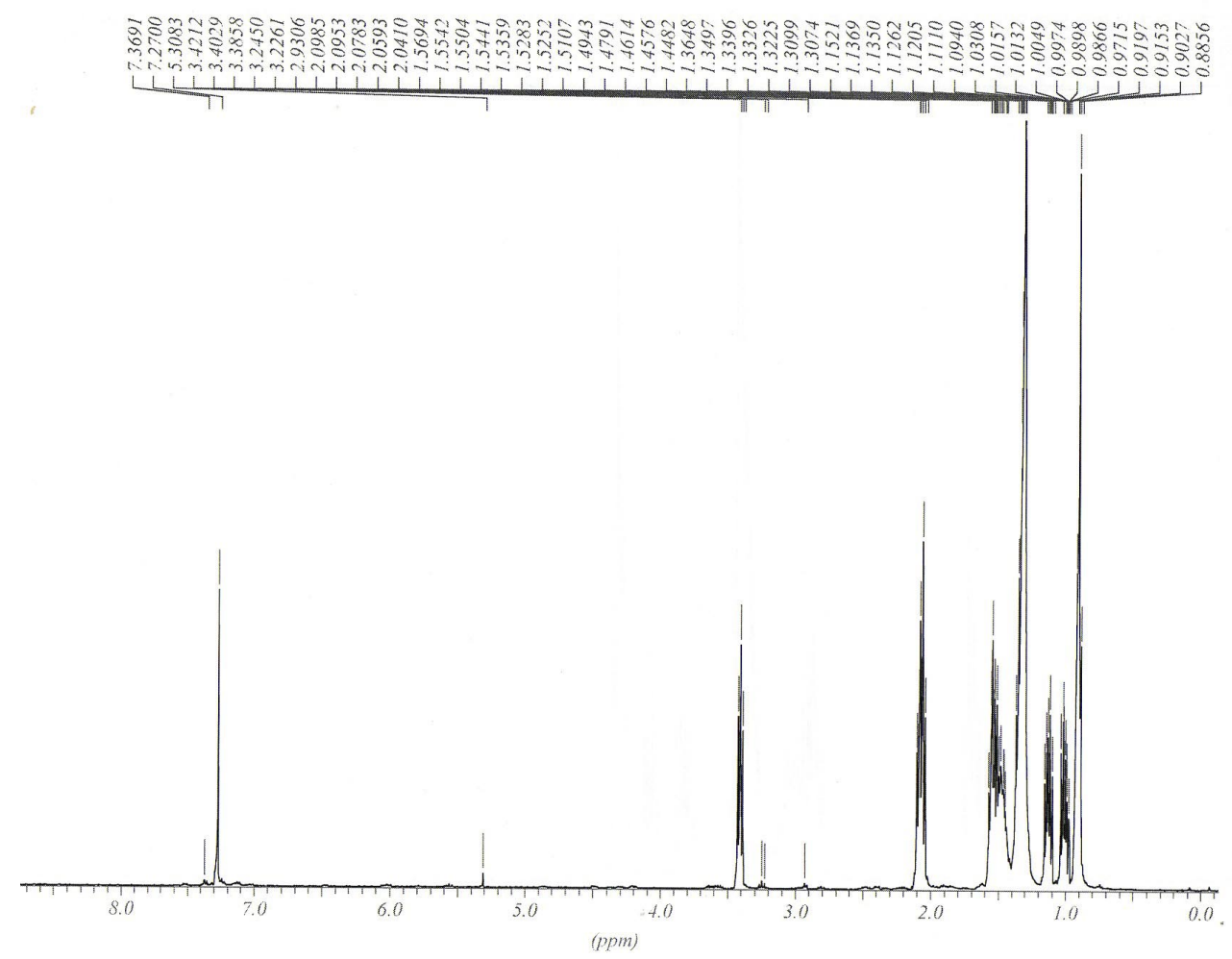

${ }^{13} \mathrm{C}$ NMR of $9 b$

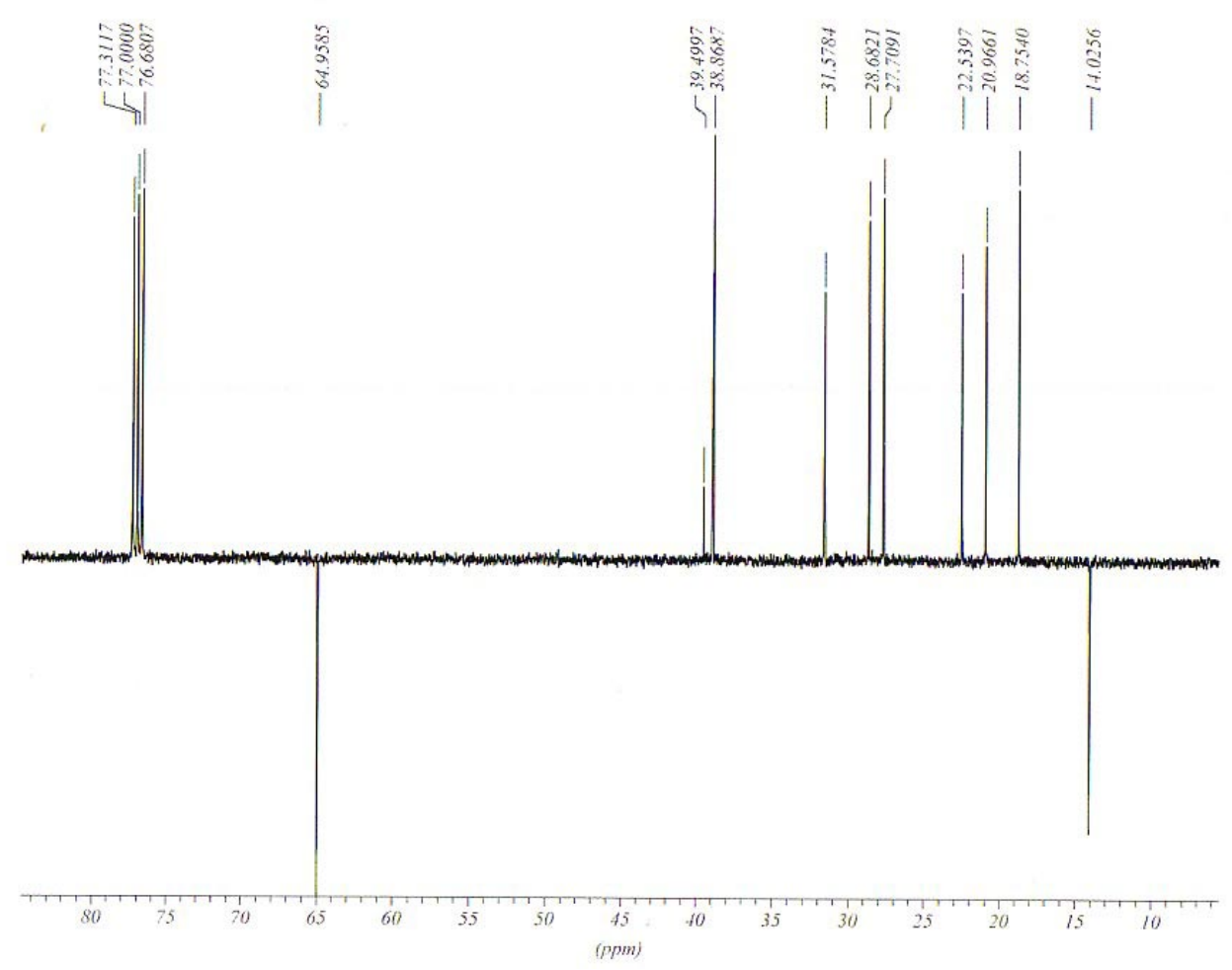


${ }^{1} \mathrm{H}$ NMR of $9 e$

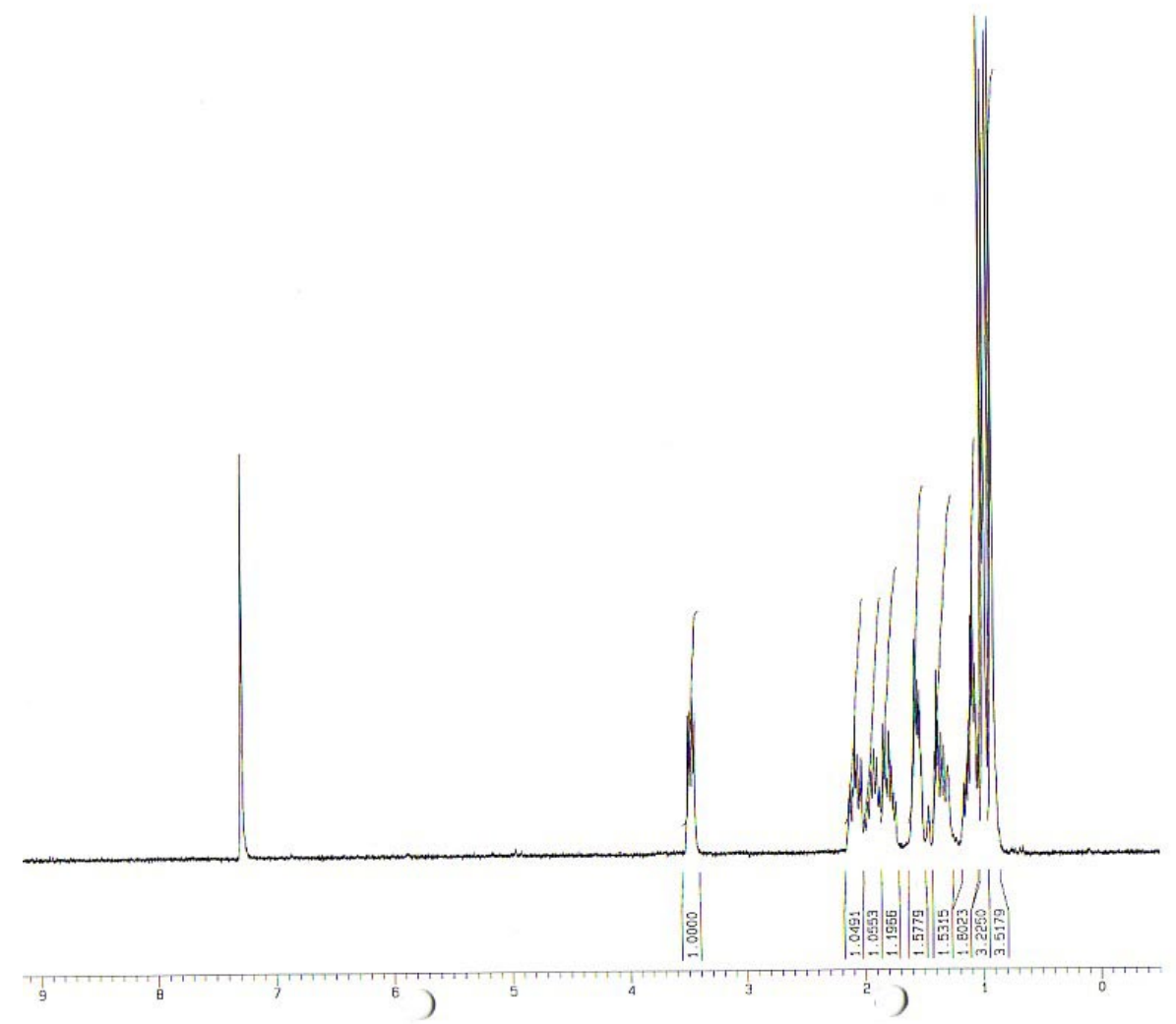

${ }^{13} \mathrm{C}$ NMR of $9 e$

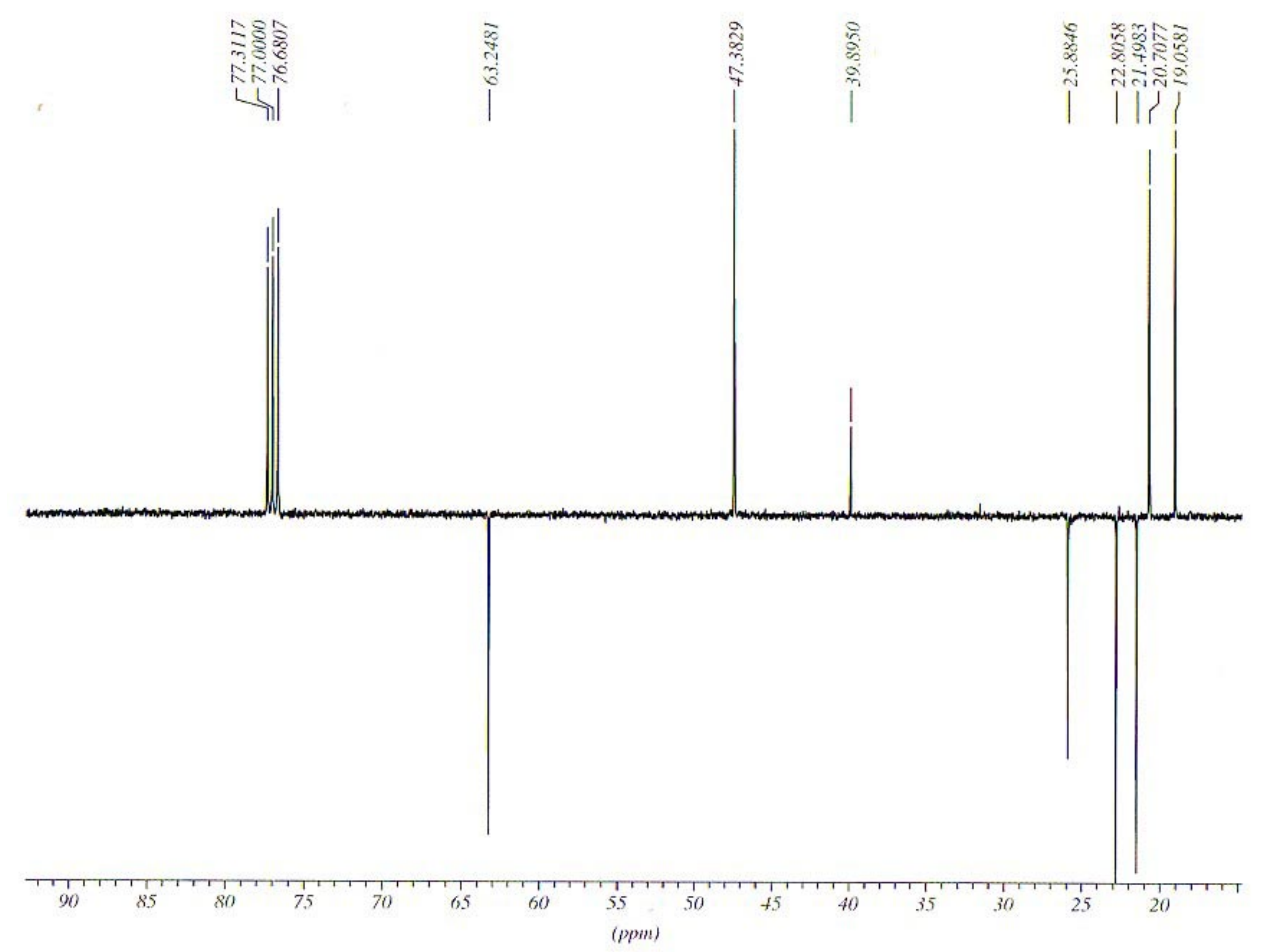




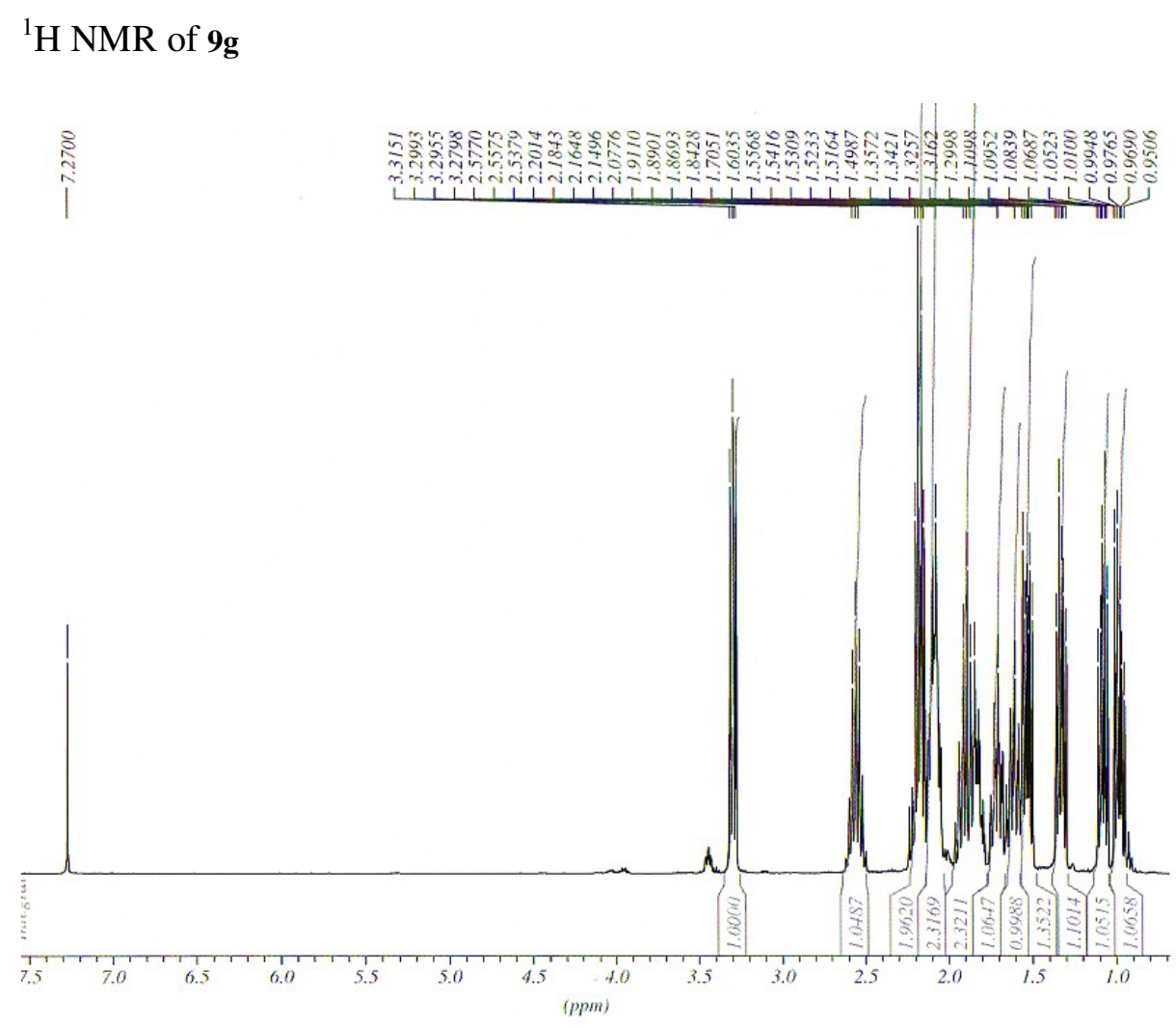

${ }^{13} \mathrm{C}$ NMR of $9 \mathrm{~g}$

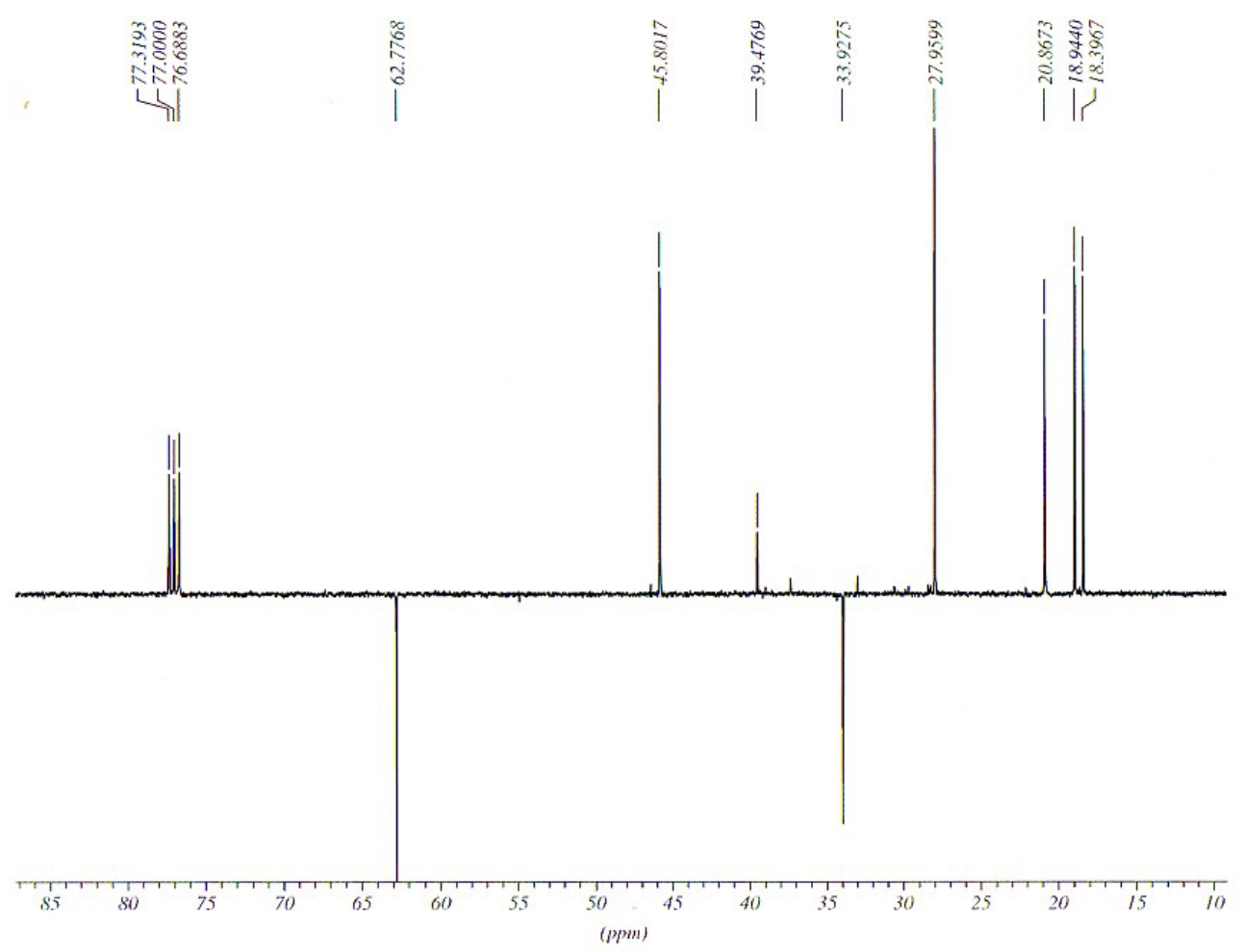


${ }^{13} \mathrm{C}$ NMR of $9 \mathbf{h}$

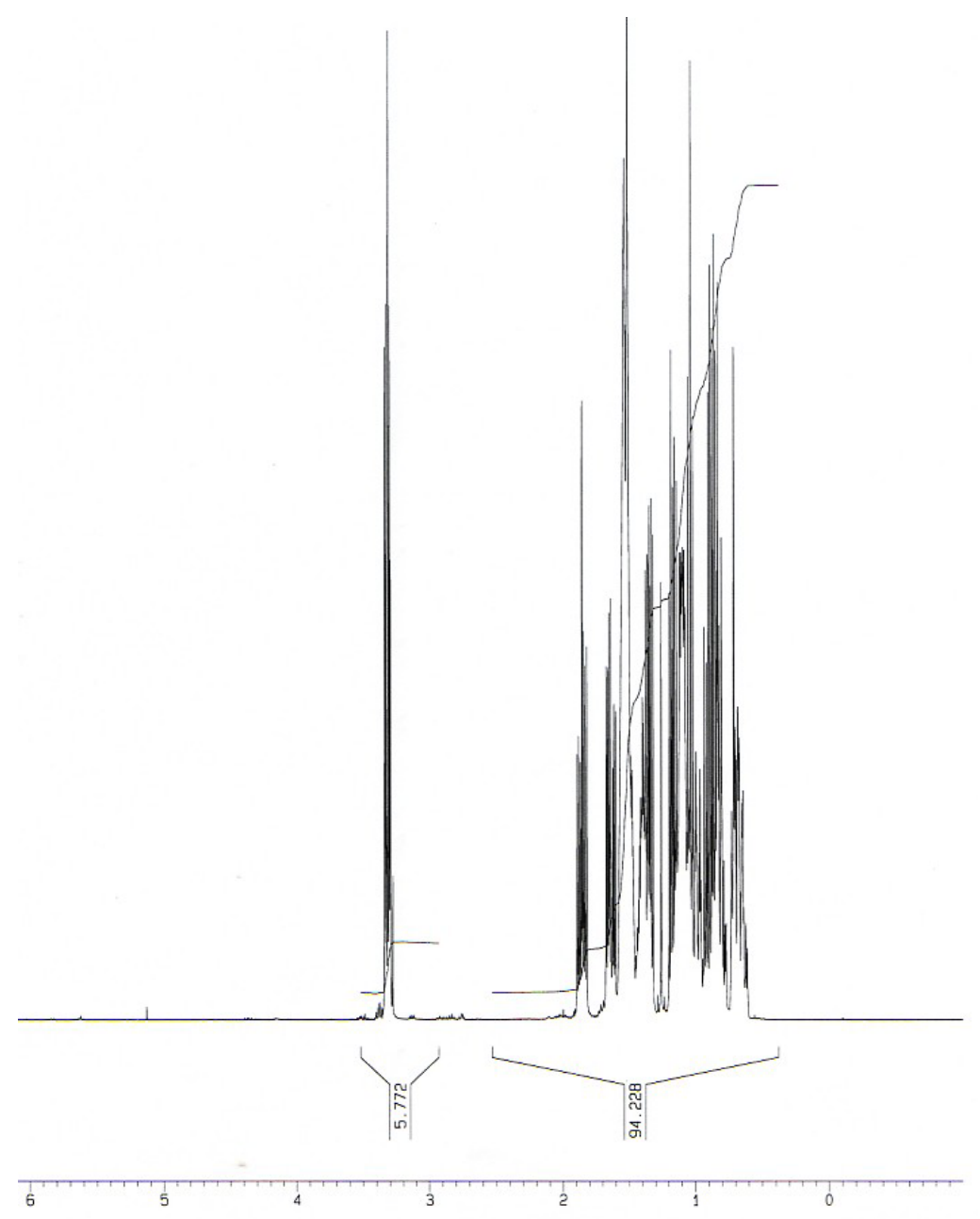

${ }^{13} \mathrm{C}$ NMR of $9 h$

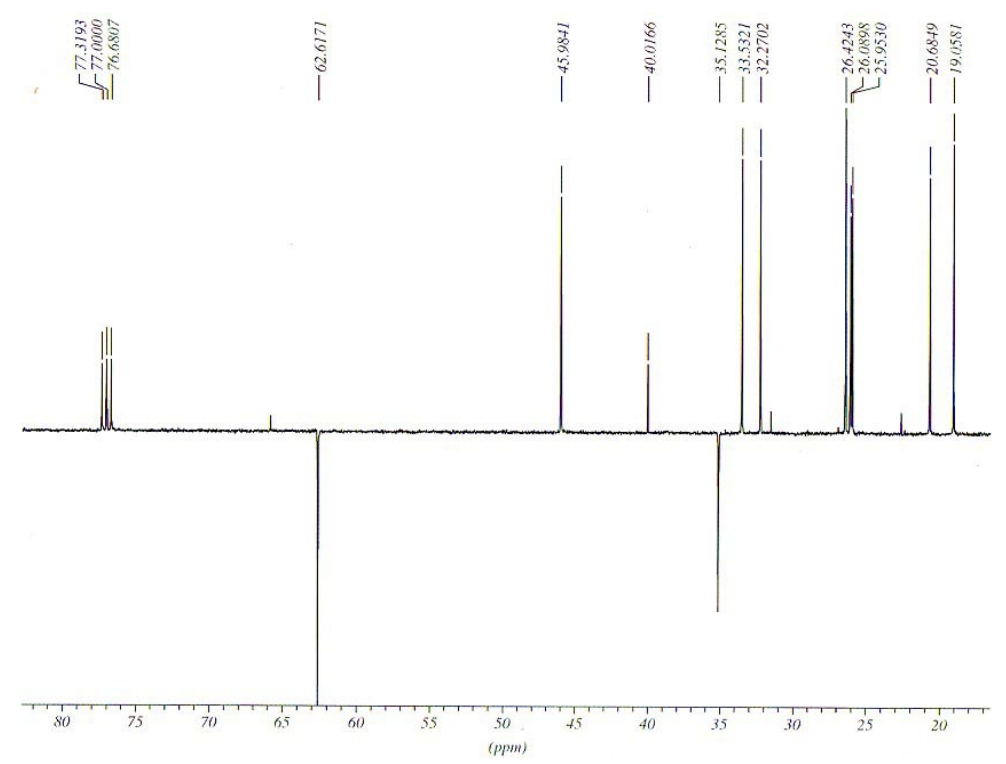




\section{${ }^{1}$ H NMR of $\mathbf{9 j}$}

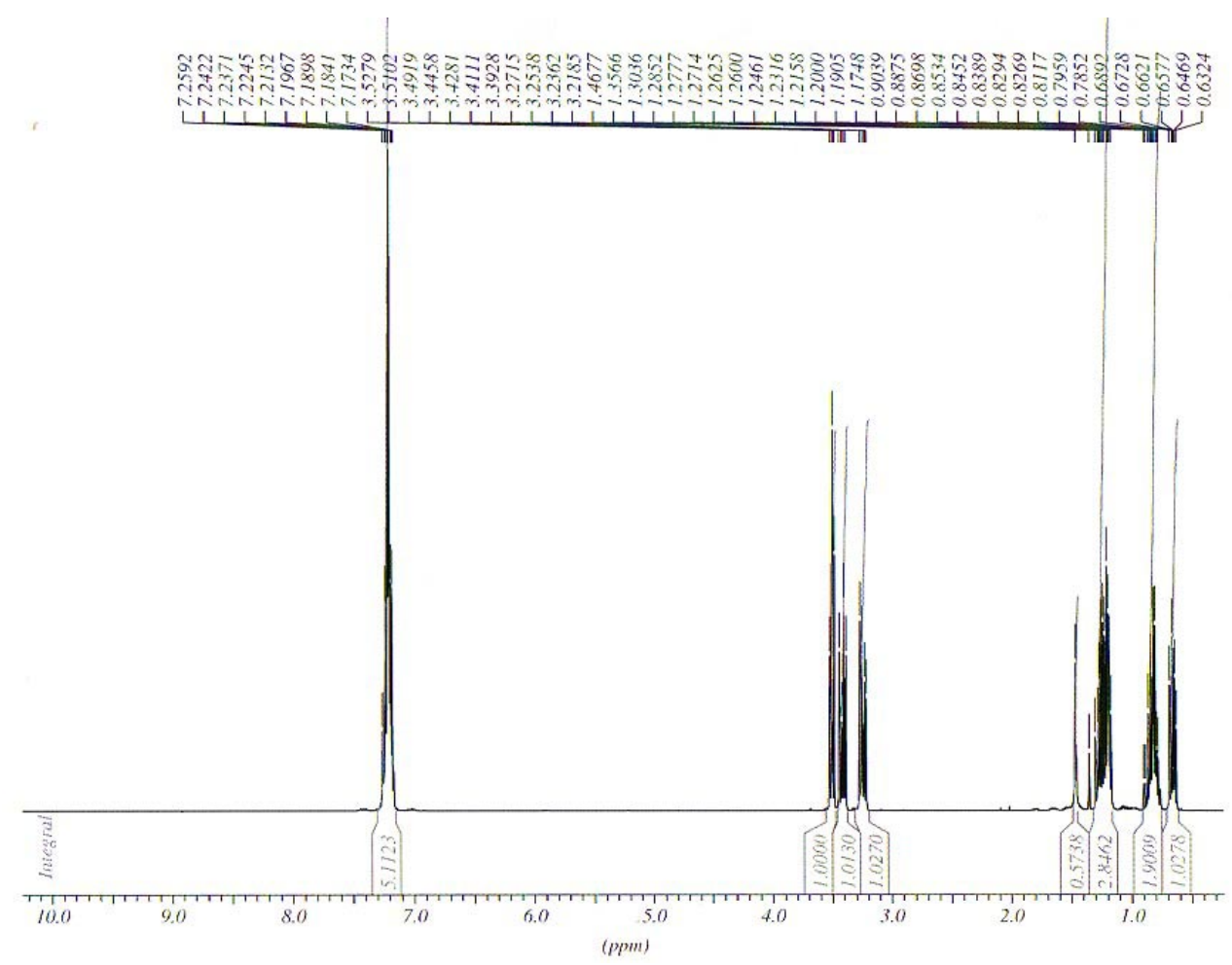

${ }^{13}$ C NMR of $9 j$

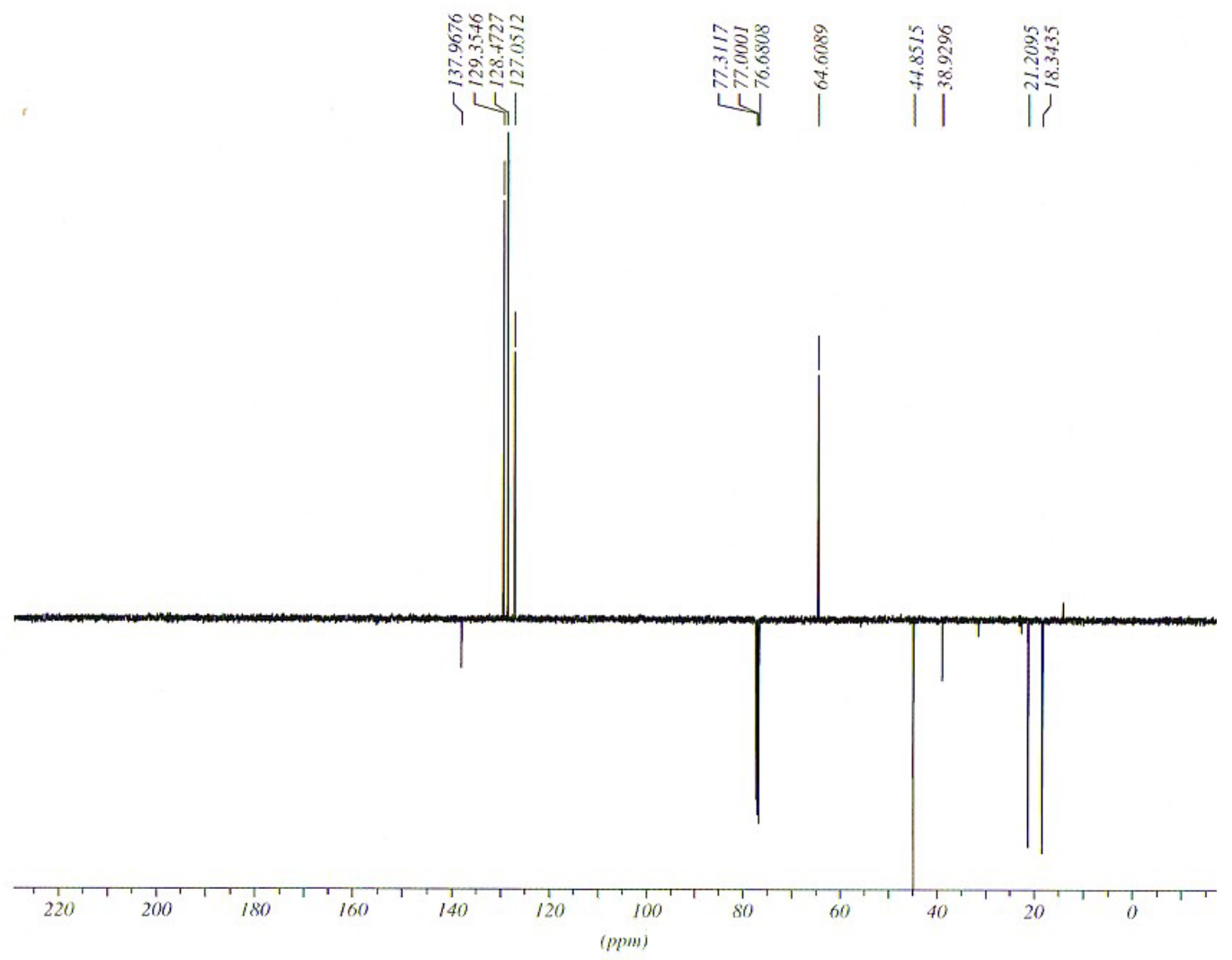

